\title{
Regional survey of temporary transvenous pacing procedures and complications
}

\section{T R Betts}

Correspondence to: Dr Timothy R Betts, Wessex Cardiothoracic Centre, Mailpoint 46, Southampton General Hospital, Tremona Road, Southampton SO16 6YD, UK: timbetts@compuserve.com

Submitted

24 February 2003

Accepted 5 April 2003

\begin{abstract}
Objective: A prospective regional survey was carried out to describe the current practice of temporary transvenous pacing in five hospitals in the Wessex region and identify factors that predispose to complications.

Methods: Data were collected on patient characteristics, pacing indication and setting, operator grade, training, experience and supervision, venous access, procedure time, duration of pacing, complications, and eventual outcome.

Results: A total of 144 procedures were performed on 111 patients (age 75 (12) years). Median procedure time was $30(1-150)$ min. Trainees performed $129(91.5 \%)$ procedures. The senior physician present was a cardiologist/cardiology trainee for $65 / 144(45.1 \%)$, and had experience of $>20$ procedures for $81 / 144(57.9 \%)$. Venous access was by the subclavian in $52(46.8 \%)$, internal jugular in $37(33.3 \%)$ and femoral in $22(19.8 \%)$, requiring multiple stabs or multiple sites in $41(33.1 \%)$. Pacing wires remained in place for a median of $2(0.04-20)$ days.

Overall procedure times were shorter for cardiologists/cardiology trainees (24[1-90] v 45[10-150] $\min , p<0.0001)$, and experienced physicians (30[1-150] v 40[10-120] min, $p<0.01)$. There were 50 complications in $46 / 144(31.9 \%)$ procedures, affecting $31 / 111(27.9 \%)$ patients. Immediate complications were less common with experienced physicians (1/81 v 5/59, $\mathrm{p}<0.05)$. Infection occurred more often with wires left in situ for $>48$ hours $(17 / 86 \vee 2 / 55, \mathrm{p}<0.01)$ and with longer procedure times $(55[8-150]$ v $30[1-120] \mathrm{min}, \mathrm{p}<0.005)$. No factors predicted displacement, which occurred at a median time of $1(0.04-8)$ day. Complications delayed permanent pacemaker insertion in $19 / 63(22.9 \%)$ patients.

Conclusions: Temporary pacemaker insertion is performed by physicians with variable experience and training. The presence of an experienced cardiologist/cardiology trainee and decreasing the time that pacing wires remain in situ may reduce complications.
\end{abstract}

nsertion of a temporary transvenous pacemaker may be performed as an urgent procedure in the setting of acute haemodynamic collapse secondary to bradyarrhythmias or tachyarrhythmias, or as a prophylactic measure in high risk patients undergoing interventional procedures. ${ }^{1}$ The procedure may be performed in a wide range of settings, by operators with varying skills, training, technical knowledge, and experience. ${ }^{2}{ }^{3}$ Previous studies have demonstrated high complication rates with little change over the last two decades. ${ }^{3-6}$ Studies performed in the UK were carried out before the introduction of the specialist registrar training grade. The present study was undertaken to determine whether the incidence of complications has changed with increasing physician numbers and a greater emphasis on subspecialty training. Operator and technical factors were also examined to identify current practices that may influence procedure outcome.

\section{METHODS}

Between January and September 1999 a prospective study was performed at five hospitals in the Wessex region (four district general hospitals and the regional cardiothoracic centre). All temporary pacing procedures were performed after obtaining informed consent from the patient unless their condition or the urgency of the occasion necessitated immediate pacing. After each pacing procedure, a physician completed a form which documented demographic details, the indication for pacing, who performed and who supervised the procedure, plus operator experience and subspecialty. If more than one operator performed the procedure the most senior physician present was noted. Operator seniority in ascending order was house officer, senior house officer, registrar, specialist registrar, staff grade, and consultant. Experienced physicians were those who had performed at least 20 temporary pacing procedures, inexperienced physicians were those who had performed less than 20 procedures. Cardiologists/cardiology trainees were defined as those specialist registrars who were in a cardiology training programme, or consultants who had a specialist interest in cardiology. Procedure details, including venous access site, procedure duration, fluoroscopy time, sterile techniques, patient cooperation, and immediate outcomes and complications were noted. Ease of venous access was categorised into "first pass at a single venous site", "multiple stabs at a single venous site", and "multiple venous sites attempted".

The form accompanied the patient throughout the duration of the temporary pacemaker period to record late complications and outcomes, including possible permanent pacemaker implantation. Complications recorded were ventricular arrhythmias, arterial puncture, pneumothorax, pericardial effusion (confirmed by echocardiography), pacing wire displacement resulting in loss of capture that required repositioning or resiting, local infection (erythema and purulent discharge without systemic symptoms), and systemic infection (fever with other potential causes ruled out). If the temporary pacemaker required repositioning or resiting the initial form was completed and a new form begun.

Statistical analysis was performed using SPSS for Windows version 11. Continuous data were analysed using the Student's $t$ test, analysis of variance, Mann-Whitney U or Kruskal-Wallis test where appropriate. Nominal data were analysed using $\chi^{2}$ 
Table 1 Patient, operator, and procedure characteristics; values are number (\%) unless stated otherwise

\begin{tabular}{|c|c|c|}
\hline Parameter & $\begin{array}{l}\text { All } \\
\text { procedures }\end{array}$ & $\begin{array}{l}\text { Initial } \\
\text { insertions }\end{array}$ \\
\hline Total & 144 & 111 \\
\hline Mean (SD) age (years) & 75.5 (1 1.4) & $75.2(12.3)$ \\
\hline $\begin{array}{l}\text { Median (range) procedure duration } \\
\text { (min) }\end{array}$ & $30.0(1-150)$ & $30.0(1-120)$ \\
\hline Median (range) screening time (min) & $3.4(1-60)$ & $3.0(1-30)$ \\
\hline Median (range) threshold (volts) & $0.5(0.1-10)$ & $0.5(0.1-10)$ \\
\hline $\begin{array}{l}\text { Median (range) pacing wire in situ } \\
\text { (days) }\end{array}$ & $2.0(0.1-20)$ & $2.0(0.1-20)$ \\
\hline \multicolumn{3}{|l|}{ Sex } \\
\hline Male & $90(63.4 \%)$ & $70(63.1)$ \\
\hline Female & $52(36.6 \%)$ & 41 (36.9) \\
\hline \multicolumn{3}{|l|}{ Indication } \\
\hline Advanced atrioventricular block & & $68(61.3)$ \\
\hline Sinus node disease & & $11(9.9)$ \\
\hline Bradycardia (non-specific) & & $8(7.2)$ \\
\hline Cover a procedure & & $22(19.8)$ \\
\hline Ventricular tachycardia & & $2(1.8)$ \\
\hline \multicolumn{3}{|l|}{ Urgent } \\
\hline Yes & $106(74.6)$ & $87(79.8)$ \\
\hline No & $36(25.4)$ & $22(20.2)$ \\
\hline \multicolumn{3}{|l|}{$\begin{array}{l}\text { In setting of acute myocardial } \\
\text { infarction }\end{array}$} \\
\hline Yes & 14 (9.7) & $12(10.8)$ \\
\hline No & $130(90.3)$ & $99(89.2)$ \\
\hline \multicolumn{3}{|l|}{ Senior operator grade } \\
\hline House officer & $3(2.1)$ & 0 \\
\hline Senior house officer & $54(38.3)$ & $43(39.4)$ \\
\hline Registrar & $72(51.1)$ & $56(51.4)$ \\
\hline Staff grade & $2(1.4)$ & $1(0.9)$ \\
\hline Consultant & $10(7.1)$ & $9(8.3)$ \\
\hline \multicolumn{3}{|l|}{ Senior grade present } \\
\hline Senior house officer & $4(2.7)$ & $2(1.8)$ \\
\hline Registrar & $121(84.6)$ & $96(87.3)$ \\
\hline Staff grade & $2(1.4)$ & $1(0.9)$ \\
\hline Consultant & $16(11.2)$ & $11(10)$ \\
\hline \multicolumn{3}{|l|}{ Experience (years) } \\
\hline$<20$ & $59(42.1)$ & $50(45.1)$ \\
\hline$>20$ & $81(57.9)$ & $61(54.9)$ \\
\hline \multicolumn{3}{|l|}{ Cardiologist } \\
\hline Yes & $65(45.1)$ & $47(42.3)$ \\
\hline No & 79 (54.9) & $64(57.7)$ \\
\hline \multicolumn{3}{|l|}{ Access } \\
\hline Subclavian vein & $62(43.1)$ & $52(46.8)$ \\
\hline Internal jugular vein & $57(39.6)$ & 37 (33.3) \\
\hline Femoral vein & 25 (17.4) & $22(19.8)$ \\
\hline \multicolumn{3}{|l|}{ Ease of access } \\
\hline First pass & $83(66.9)$ & 71 (65.7) \\
\hline Multiple attempts at one site & $28(22.6)$ & $25(23.1)$ \\
\hline Multiple attempts at $>1$ site & 13 (10.5) & 12 (11.1) \\
\hline \multicolumn{3}{|l|}{ End result } \\
\hline Pacing wire in place & $142(98.6)$ & $109(98.2)$ \\
\hline Procedure abandoned & $2(1.4)$ & $2(1.8)$ \\
\hline
\end{tabular}

or Fisher's exact test where appropriate. Multivariate analysis was performed using binomial logistic regression. A p value of $<0.05$ was considered significant. Normally distributed data are presented as mean (SD), and non-parametric data as median (range).

\section{RESULTS}

A total of 144 procedures were performed on 111 patients (70 male) with a mean (SD) age of 75 (12) years. Patient, operator, and procedure characteristics are summarised in table 1 . There were 111 initial temporary pacing wire insertions, 17 repositionings (not requiring new venous access), and 16 replacements (requiring new venous access). Training grades (that is, non-consultant or staff grade physicians) performed $129(91.5 \%)$ of all procedures.

Temporary pacing was abandoned in two patients, both who subsequently died from cardiogenic shock in the setting of
Table 2 Complications; values are number (\%)

\begin{tabular}{|c|c|c|}
\hline Complication & All procedures & $\begin{array}{l}\text { Initial } \\
\text { insertions }\end{array}$ \\
\hline Arterial puncture & $2(1.4)$ & $1(0.9)$ \\
\hline Pneumothorax & $2(1.4)$ & $2(1.8)$ \\
\hline Haemopericardium & $4(2.8)$ & $3(2.7)$ \\
\hline Displacement & $23(16.0)$ & $16(14.4)$ \\
\hline Local Infection & $3(2.1)$ & $2(1.8)$ \\
\hline Systemic infection & $16(11.1)$ & $10(9.0)$ \\
\hline Patients with $\geqslant 1$ complications & $46(31.9)$ & 31 (27.9) \\
\hline Permanent pacemaker delayed & \multicolumn{2}{|c|}{$19 / 63(22.9)$} \\
\hline
\end{tabular}

acute myocardial infarction. All 142 other procedures ended with a temporary pacing wire in situ. The median pacing threshold was $0.5(0.1-10.0)$ volts. Pacing wires remained in place for a median of 2 (0.04-20) days.

Overall procedure times were shorter for cardiologists/ cardiology trainees $(24[1-90] \vee 45[10-150]$ min, $\mathrm{p}<0.0001)$, and experienced operators $(30[1-150] \vee 40[10-120] \mathrm{min}$, $\mathrm{p}<0.01)$. Procedure times for initial temporary pacing wire insertions were $45(3-120)$ min using the internal jugular vein, 25 (4-80) min using the subclavian vein, and $20(1-120)$ min using the femoral vein $(p=N S)$. The ease of venous access was similar for all three routes. The site and the ease of venous access did not differ significantly between grade of senior operator or senior physician present, physician experience, or whether the senior physician was a cardiologist/cardiology trainee. For initial temporary pacing wire insertions, procedure times were shorter if a cardiologist/cardiology trainee was present $(24[1-90] \vee 45[10-120] \mathrm{min}$ if no cardiologist/ cardiology trainee present, $\mathrm{p}<0.0001$ ), and if the senior physician present had experience of more than 20 temporary pacing procedures $(20[1-80] \vee 45[10-120] \mathrm{min}$ if $<20$ procedures experience, $\mathrm{p}<0.01)$. In addition, for initial temporary pacing wire insertions, fluoroscopy times were shorter if a cardiologist/cardiology trainee was present $(3.0[1-12] v$ $4.0[1-60] \mathrm{min}$ if no cardiologist/cardiology trainee present, $\mathrm{p}<0.005)$ and if the senior physician present was a consultant $(0.5[1-5] \vee 3.6[1-30]$ min if the senior physician was a registrar, $\mathrm{p}<0.05)$. Procedure duration was shorter at the regional centre (where all were performed with a cardiologist/ cardiology trainee registrar present or as the sole operator) than district hospitals (18[4-60] $v 45[1-120], \mathrm{p}<0.01)$.

Reported complications are listed in table 2 . There were 50 complications in $46 / 144(31.9 \%)$ pacing procedures, affecting $31 / 111(27.9 \%)$ of patients. Patient age, the presence of acute myocardial infarction, the urgency of the procedure, the grade of the senior operator and physician present, operator experience and cardiology subspecialisation, procedure duration, access route, ease of access, patient cooperation, and whether the procedure was performed in the regional centre or district hospital were not univariate or multivariate predictors of a procedure being associated with an overall complication. Immediate complications (arterial puncture, pneumothorax, or haemopericardium) were less common with experienced operators than inexperienced operators $(1 / 81 v 5 / 59, \mathrm{p}<0.05)$ by univariate analysis but not by multivariate analysis using binary logistic regression $(p=0.054)$.

The occurrence of local or systemic infection was not predicted by patient age, the presence of acute myocardial infarction, the urgency of the procedure, the grade of the senior operator and physician present, operator experience, cardiology subspecialisation, access route, ease of access, or patient cooperation. The length of time that pacing wires were left in situ was longer for wires that developed local or systemic infection than those that did not $(4[1-11] v 2[0.04-20]$ days, $\mathrm{p}<0.005)$. Infection occurred in $17 / 86$ pacing wires left in situ 
for more than 48 hours compared with 2/55 wires left in situ for less than 48 hours $(p<0.01)$. The procedure times for pacing wires that were complicated by systemic infections were significantly longer than those that did not develop systemic infection $(55[8-150] v 30[1-120] \mathrm{min}, \mathrm{p}<0.005)$. Using multivariate analysis with binomial logistic regression, longer procedure time and duration that the pacing wire remained in situ remained predictors of the occurrence of infection. There were no variables that predicted temporary wire displacement. The median time to displacement was 1 (0.04-8) day.

Insertion of a permanent pacemaker was delayed by a complication in $19 / 63(22.9 \%)$ patients who went on to receive a permanent system.

\section{DISCUSSION}

The present study demonstrates that there is considerable variation in temporary pacing procedures regarding operator grade, training and experience, as well as in the techniques used. Almost one third of procedures were associated with complications. These data are similar to those reported in surveys of temporary pacing performed in the 1970s, 1980s, and early 1990s. ${ }^{35-7}$ In the UK, temporary pacing has traditionally been performed by senior house officer or registrar training grades, many of who are not cardiology trainees and have little experience in either central venous cannulation or temporary wire manipulation. ${ }^{23}$ Although the presence of a consultant remains uncommon, the present study reveals that registrars, rather than senior house officers, are now most often the senior grade present. ${ }^{3}$ Despite the higher seniority, the majority of senior physicians and operators were not cardiology trainees and only $57.9 \%$ of senior physicians present had experience of greater than 20 temporary pacing procedures. Thus, although the introduction of the specialist registrar training grade may now mean that the majority of pacing is performed by a higher training grade, many operators remain inexperienced and in most hospitals there are not enough cardiologists or cardiology trainees available to provide a dedicated temporary pacing service.

The most common route of venous access remains the subclavian vein. Although almost all trainee doctors feel able to perform subclavian vein punctures, many do not feel comfortable attempting the internal jugular route. ${ }^{2}$ American College of Cardiology and British Cardiac Society Guidelines for temporary pacing recommend the internal jugular route, particularly for inexperienced operators. ${ }^{89}$ The internal jugular route is preferable in the setting of impaired coagulation (for example, after thrombolysis), has a lower risk of pneumothorax, and leaves the subclavian vein free for insertion of a permanent pacemaker system should it be required. Of note, no route of venous access had a higher complication rate. In particular, femoral pacing wires did not have a higher incidence of displacement or infection and there were no reported lower limb deep vein thromboses.

None of the central venous cannulation procedures in this survey were performed under ultrasound guidance. Although this technique has recently been recommended for most elective and urgent central venous cannulation procedures, it requires the operator to learn yet another skill. Whether it is taken up by general medical trainees who may not perform central venous cannulation on a daily basis (unlike anaesthetists for example), and leads to a reduction in cannulation complications, remains to be seen.

Unlike earlier studies, the present study did not report any malignant ventricular arrhythmias requiring urgent treatment during temporary pacing wire insertion or repositioning. This may have been due to the relatively low number of procedures $(10.8 \%)$ that were performed in the setting of an acute myocardial infarction. This finding contrasts many earlier studies, in which the majority of temporary pacing procedures were in the setting of acute myocardial infarction. ${ }^{467}$ The reduction in the need for temporary pacing in this scenario may reflect the increased use of reperfusion therapies.

The overall complication rate was similar to that reported in previous studies, with pacing wire displacement and infection being the most common. ${ }^{35-7}$ Immediate complications were related to operator rather than patient factors, with greater experience and cardiology training resulting in shorter procedure times and fewer early complications. However, the small number of immediate complications limits the validity of these findings and explains why statistical significance was achieved only with univariate analysis. Operator and technique related factors did not predict the development of temporary wire displacement, which usually occurred within the first 24 hours. It is possible that conditions affecting the patient after the temporary pacing procedure, such as morbidity, mobility, and post-procedure care may influence displacement rates. As may be expected, infection occurred more often after longer procedures (which are also influenced by operator experience and training) and the longer a pacing wire remained in situ. Further studies that examine postoperative pacing site care, patient mobility, and the use of prophylactic antibiotics after long procedures are warranted.

One consequence of the high complication rate was that $23 \%$ of patients who required permanent pacing had their procedure delayed. Winner and Boon found that 36\% of patients transferred for permanent pacing had a major complication and an additional $14 \%$ had a minor complication, with $17 \%$ of patients arriving at the regional centre without a functioning temporary pacing wire. ${ }^{5}$ With the increasing availability of permanent pacing at district general hospital level and the transient, correctable nature of many bradyarrhythmias, patients who may require a permanent pacemaker should only receive a temporary pacing wire if absolutely necessary. ${ }^{10}$ Improvements in temporary pacing equipment, such as the use of balloon flotation catheters or external pacing pads, may result in fewer complications while preserving patient safety. ${ }^{11}{ }^{12}$ Conversely, the decreasing need for temporary pacing, combined with the increase in numbers of trainee doctors, will inevitably result in less experience for individual physicians, perhaps taking temporary pacing in the UK beyond the remit of the general internal medicine trainee. ${ }^{13}$

\section{CONCLUSIONS}

Temporary transvenous pacemaker procedures are still performed by physicians with variable experience and training and are associated with a high complication rate. The present study suggests that procedures performed or supervised by cardiologist/cardiology trainees with experience of greater than 20 procedures have shorter procedure and fluoroscopy times and are less likely to result in complications. Reducing the duration that temporary pacing wires are in situ may prevent subsequent infection and avoid delay in permanent pacemaker insertion.

\section{ACKNOWLEDGEMENTS}

The author would like to thank the doctors and nursing staff of the coronary care units and cardiac catheter laboratories at Southampton General Hospital; St Mary's Hospital, Portsmouth; the Royal United Hospital, Bath; Salisbury General Hospital; and Princess Margaret Hospital, Swindon, for their assistance in performing the survey.

\section{REFERENCES}

1 Gammage MD. Temporary cardiac pacing. Heart 2000;83:715-20.

2 Davis GK, Roberts DH. Experience and training in temporary transvenous pacing. J R Coll Physicians Lond 1996;30:432-4

3 Murphy JJ. Current practice and complications of temporary transvenous cardiac pacing. BM 1996;312:1134. 
4 Austin JL, Preis LK, Crampton RS, et al. Analysis of pacemaker malfunction and complications of temporary pacing in the coronary care unit. Am J Cardiol 1982;49:301-6.

5 Winner S, Boon N. Clinical problems with temporary pacemakers prior to permanent pacing. J R Coll Physicians Lond 1989;23:161-3.

6 Hynes JK, Holmes DR Jr, Harrison CE. Five-year experience with temporary pacemaker therapy in the coronary care unit. Mayo Clin Proc 1983;58:122-6.

7 Jowett NI, Thompson DR, Pohl JE. Temporary transvenous cardiac pacing: 6 years experience in one coronary care unit. Postgrad Med J 1989;65:211-5

8 ACP/ACC/AHA Task Force on Clinical Privileges in Cardiology Clinical competence in insertion of a temporary transvenous ventricular pacemaker. J Am Coll Cardiol 1994;23:1254-7.
9 Medical Practice Committee and Council of the British Cardiac Society. Choice of route for insertion of temporary pacing wires: recommendations of the Medical Practice Committee and Council of the British Cardiac Society. Br Heart J 1993;70:592.

10 Hildick-Smith DJ, Petch MC. Temporary pacing before permanent pacing should be avoided unless essential. BM 1998:317:79-80.

11 Madsen JK, Meibom J, Videbak R, et al. Transcutaneous pacing: experience with the Zoll noninvasive temporary pacemaker. Am Heart J $1988 ; 116: 7-10$

12 Ferguson JD, Banning AP, Bashir Y. Randomised trial of temporary cardiac pacing with semirigid and balloon-flotation electrode catheters. Lancet 1997;349:1883.

13 Petch MC. Temporary cardiac pacing. Postgrad Med J 1999;75:577-8.

\section{IMAGES IN MEDICINE.}

\section{Cushing's syndrome due to an adrenocortical carcinoma}

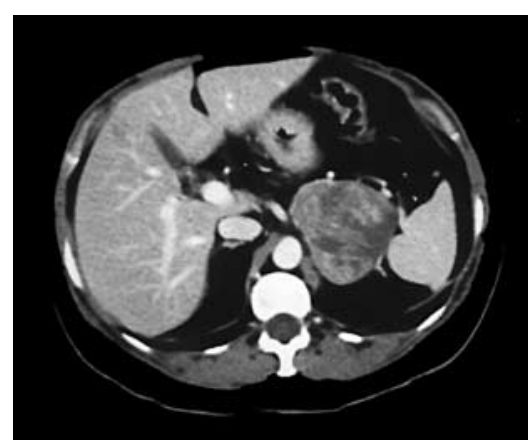

Figure 1 Abdominal computed tomography showing left adrenal tumour.
46 year old woman presented with a short history of hirsutism, facial plethora, $\triangle$ amenorrhoea, progressive weight gain, and hypertension. Cushing's syndrome was suspected and confirmed biochemically. Urine free cortisol concentrations measured as cortisol/creatinine ratios on two successive 24 hour urine collections were raised at 80 and 169 $\mathrm{nmol} / \mathrm{mmol}$ respectively (reference range $5-55$ ).

High dose dexamethasone suppression test was done (dexamethasone $2 \mathrm{mg}$ orally every six hours for 48 hours ). Basal serum cortisol was $599 \mathrm{nmol} / \mathrm{l}$ and failed to suppress after 48 hours, remaining raised at $555 \mathrm{nmol} / \mathrm{l}$. This was suggestive of primary adrenal disease as cortisol levels normally suppress to less than $50 \%$ of basal levels in pituitary driven Cushing's disease. Serum testosterone was raised at $7.2 \mathrm{nmol} / \mathrm{l}(0.5-2.6)$. Urinary catecholamine levels were normal. The short history and raised testosterone level was suggestive of an adrenal carcinoma. Abdominal computed tomography showed a large left adrenal tumour with central necrosis and no evidence of metastases ( see fig 1). An adrenal carcinoma was subsequently completely resected.

Primary adrenal tumours are responsible for about 10\% of cases of Cushing's syndrome. Adrenocortical carcinomas are uncommon with an incidence of 2 per million per year and occur more commonly in women. Raised androgen levels in Cushing's syndrome are suggestive of malignant adrenal tumours.

Adrenal carcinomas are rapidly progressive and have usually metastasised to the lungs and liver at diagnosis. Mitotane, an isomer of the insecticide DDT, has been used as adjunctive therapy to treat metastatic disease.

S Nag, A McCulloch

Department of Endocrinology, Bishop Auckland General Hospital, Cockton Hill Road, Bishop Auckland, Co Durham DL 14 6AD, UK; s.nag@btopenworld.com 